\title{
Strategic Environmental Assessment (SEA) Process for Green Information Technology and Management Engineering Systems towards Sustainable Education Process
}

\author{
Business Excellence Achievements
}

\begin{abstract}
Vijayan Gurumurthy Iyer ${ }^{*}$
Koneru Lakshmaiah Education Research Foundation (KLEF) Deemed To Be University and DEBM Course Co-Ordinator, the EDI of India A-2/31, Kendhriya Vihar-II, Poonamalee-Avadi Main Road, Paruthipattu, Avadi, Chennai-71, TamilNadu, India.

*Corresponding author
\end{abstract}

\begin{abstract}
In this research article, strategic environmental assessment (SEA) process for green information technology and management engineering systems has been discussed. Strategic environmental assessment (SEA) process can be broadly defined as a study of the impacts of a proposed project, plan, project, policy or legislative action on the environment and sustainability. In this research, SEA process has been aimed to incorporate environmental and sustainability factors in to project planning and decision-making process such as project formulation and appraisal of Matsushita Carbon Company (MCC) plant in 1979 at Tada and cotton roller ginning plant as well as certain other projects that included policies, programs, plans and legislative actions. Sustainable education process is a kind of development that meets the needs of the present without compromising the ability and efficacy of future generations to meet their own educational needs. Environmental Impact Assessment (EIA) process can be defined as the systematic study of the potential impacts (effects) of proposed projects, plans, programs, policies or legislative actions relative to the physical-chemical, biological, cultural, and socioeconomic components of the total environmental product life cycle. The primary purpose of the EIA process is to encourage the consideration of the environment in Organizational's planning and decision-making process (OPDM) and to arrive at actions that are environmentally compatible. OPDM process should include the integrated consideration of technical or engineering, economic, environmental, safety, and health, social and sustainability factors to achieve business excellence. Prior to the National Environmental Policy Act (NEPA) process in 1970 in the USA, technical and economic factors dominance the World's projects. The objective of the study design conceptualization of SEA process based on fifteen number of sustainable detailed project reports (DPRs) submitted by the extension learners of Diploma in Entrepreneurship and Business Management (DEBM) course conducted by the Entrepreneurship Development Institute of India (The EDI of India) during the research year (RY) 1999 to 2018 under the author's counsellorship. The design of the study is cross sectional. Environmental Health Impact Assessment (EHIA) process has been conducted for projects to consider the safety and health impacts to mitigate psychological health loadings on workers and nearby residents. Social Impact Assessment (SIA) process can be defined as the systematic identification and
\end{abstract}

evaluation of the potential social impacts (effects) of proposed projects, plans, programs, or legislative action such that social consideration is encouraged in OPDM process and to arrive at actions that are socially compatible. SEA process concerns to environment and sustainability effects in OPDM process and arrive at proposed projects, plans, programs, and legislative actions that are compatible with respect to environment and sustainability issues. International EIA process required multidisciplinary approach that has been conducted very early stage of Japanese Matsushita carbon rod project in 1982 for strategic environmental assessment. The paper highlights SEA process conducted for certain projects that based on operation and process approach and associated studies for sustainable educational development. Engineering product environmental lifecycle analysis (LCA) has been conducted for identifying and measuring the impact of certain industrial products on the environment by means of mass and energy balance methods. LCA considers the activities related to raw materials, transformation, ancillary materials, equipment, method, market, man power, production, use, disposal and ancillary equipment. As far as safety is concerned personal protective equipment and materials (PPEMs) that include garments, clothing, gloves, safety shoes, hard hats, safety glasses, shields, respirators, full aprons, safety belts, and other safety items which must be used by an individual. Such equipment is important for personal protection and for safety. It is the manager's and supervisor's responsibility to ensure that they are used. The enactment of worker's compensation law and occupational disease law shall increase materially the cost of insurance to industry. The increased cost and the certainty with which it is applied will put a premium on accident-prevention work. This cost can be materially reduced by the installation of safety devices. Research experience has shown that approximately $80 \%$ of all the industrial accidents are preventable. EIA and EHIA processes have been conducted for research projects to consider the safety and health impacts to mitigate psychological health loadings on workers and nearby residents. SEA system is a potentially useful element of good environmental management and sustainable development; however, as currently practiced in industries adopted information technology and management engineering, it is far from perfection. Emphasis should be given in industries involving the green information technology and management engineering 
systems on maintaining economic viability of the operation, while in turn taking care to preserve the ecological and social sustainability of the country. International EIA process required multi-disciplinary approach that has been conducted very early stage of Indo-Matsushita Midget electrode project in 1982 at Tada for technical, economic, ecological and social sustainability [6].

Keywords-green information technology; sustainable education; management engineering; sustainability; sustainable innovation

\section{INTRODUCTION}

Sustainable education process is a kind of process development that meets the needs of the present without compromising the ability and efficacy of future generations to meet their own educational needs.

Strategic environmental assessment process (SEA) can be defined as the systematic identification and evaluation of the potential strategic environmental impacts of proposed projects, plans, programs, or legislative actions relative to the physicalchemical, biological, cultural, and socio-economical components of the total strategic environment. The primary purpose of the SEA process is to encourage the consideration of the sustainability in planning and design making process and to ultimately arrive at actions which are sustainably compatible concerns to green information technology and management engineering systems.

The legislation of EIA process was established in 1970 by the enactment of the National Environmental Policy Act (NEPA) in the USA [5]. This was first time that EIA process in industries became an official tool to protect the environment. Three of the significant terms while complying with the requirements of NEPA process are "environmental inventory", "environmental impact assessment process", and "environment impact statement". EIAs of design and conceptualization were undertaken to protect environment during the year 1950 in Japan, Europe and North America [2]. The purpose of the EIA process is to encourage the consideration of the environment in organizational planning and decision-making process. Historically, the choice of proposed projects, policies, plans, programs, permits, procedures or legislations was primarily based on only one criterion called economic viability. Today, it is necessary to consider three criteria of economic, environmental and social viabilities. Environment coupled with quality management (EQM) is an intricate managerial approach that was the targeted research area to achieve socio-economic improvement and sustainability based on the triple bottom-line approach (economical, environmental and social) feasibility studies.

\section{MATERIALS AND METHODS}

SEA process is a predictable process that is devised in to two phases. The first phase is called initial environmental and sustainability evaluation (IESE) and the second phase is environmental and sustainability impact studies (ESIS). IESE has been carried out for Japanese Matsushita carbon company's proposed project, plan, program, policy, permit, procedure, and legislative action in India to determine whether potentially adverse effects on environment and sustain efficacy with respect to physical, chemical, biological, economical, socio-economic environment and on human health and wellbeing are significant or whether mitigation measures can be adopted to reduce or eliminate adverse environmental and sustainability impacts. Detailed SEA procedure can be called as ESIS that was applied to identify and evaluate the environmental and sustainability consequences both beneficial and adverse impacts to ensure that the environmental and sustainability impacts were taken in to consideration in organization's planning and decision making (OPDM) process. SEA process is designed to identify and predict the potential impacts of the physical, biological, ecological, socio-economic, cultural environment and on human health and well-being are adequately protected [6]. Given below some of the methods and techniques applied for the sustainable project formulation and appraisal of fifteen DEBM extension learners of The EDI of India attached with the professional counsellor and coordinator for the midget electrode (Battery carbon rod) project. Expert judgment and stakeholders' sentiments.

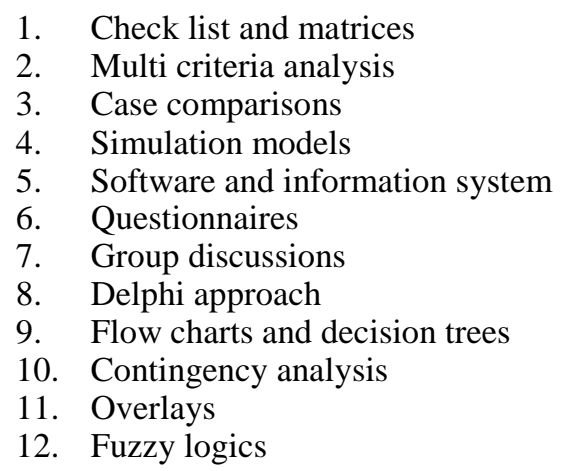

Environment and sustainability compliance requirements have been identified and evaluated systematically in these projects (http://debm-ediiindia.ac.in/counsellors/student record). Fifteen DPRs of DEBM Learners were formulated and appraised.

\section{A. Step-wise Structure of SEA Process}

SEA Process has been itemized by the following nine steps.

1. Preliminary activities and decision of Terms of References (TOR)

2. Scoping

3. Study of base line data

4. Strategic environmental assessment and evaluation,

5. Evaluation of alternative measures

6. Assessment of alternative measures

7. Preparation of final documents

8. Decision-making

9. Monitoring, measurement and control opportunities for resource transformation and project implementation and its strategic environmental assessment process.

\section{B. Conceptual Framework for Screening and Scoping of SEA Process}

Screening and scoping processes are the items which are employed in the SEA processes (Figure I). Three most significant items are," Strategic environmental assessment 
inventory, environmental impact assessment, strategic environmental impact assessment statement. Constructional planning and decision-making process should include the integrated consideration of technical, economic, environmental, social, safety, health and sustainability factors (Figure II).

\section{Strategic Environmental Assessment Management Plan (SEMP)}

A strategic environmental assessment management plan is a detailed plan and schedule for measures to minimize and mitigate any potential environmental and sustain efficacy impacts. SEMP should consist of a set of measurement, monitoring, control (mitigative) and institutional measures to be taken during the implementation and operation of the proposed projects to eliminate adverse environmental and sustainability impacts, offset them or reduce them to acceptable levels. Strategic environmental assessment process aims to incorporate environmental and sustainability considerations in to strategic planning and decision-making processes of the project formulation and appraisal. International EIAs are important considerations in project planning and decision-making process. It has been imperative to consider international EIAs in concrete project to mitigate $\mathrm{CO}_{2}$-induced climate warming problem and stratospheric ozone depletion problem. International EIA process is a potentially good environmental management [2].

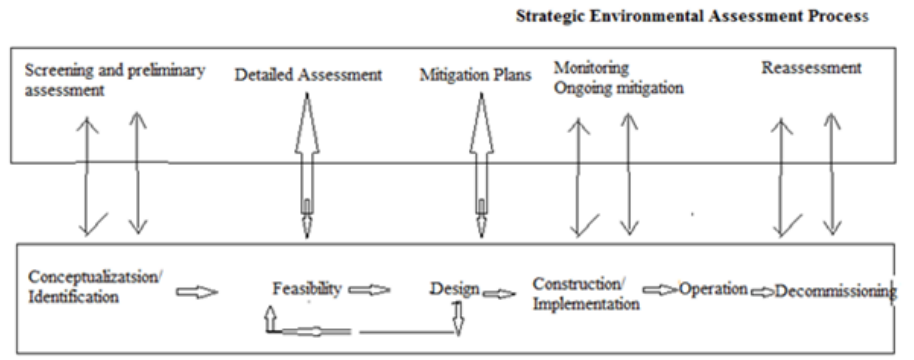

Project Life Cycle

FIGURE I. CONCEPTUAL FRAMEWORK FOR SCREENING AND SCOPING PROCESSES OF SEA PROCESS

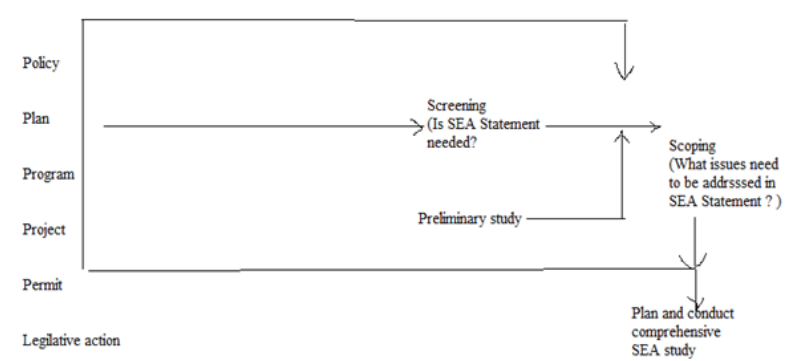

FIGURE II. STRATEGIC ENVIRONMENTAL ASSESSMENT (SEA) PROCESS AT DIFFERENT PHASES OF PROJECT LIFE CYCLE ASSESSMENT

\section{RESULTS AND DISCUSSIONS}

During the last two centuries due to the fast urbanization and industrialization along with advancement of Science, Engineering and Technology, there have been considerable developments in industrial sector with the resultant wastage of copious amount of resources and tremendous environmental stress. Subsequently, it was realized that there were many adverse impacts on environment and society. These unsustainable developments with reference to red materials that have not sustained the environmental growth. Sustainability of design and development, quality of life, safety on earth and continuous process improvement of our environment is of utmost important. Sustainable development means a kind of education development that should be occurred without damages to the environment. Hence, hectic constructional developmental activities during the last two centuries have caused considerable environmental and social impacts. These impacts have been measured, monitored and mitigated by international environmental impact assessment process (Figure III).

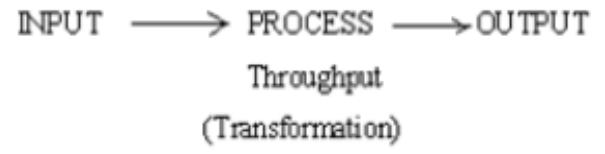

\section{FIGURE III. CONSTRUCTION MANAGEMENT BY PROCESS APPROACH}

International EIAs are important in an international project planning and decision-making process that mitigates potential environmental impacts in more than one country (Ref. IndoMatsushita Carbon Company limited). The use of sustainable technology and management in environmental and sustainability matters in two areas that is sustainable development with global problems and prevention technologies that are designed to reduce the environment effects of products and processes (Figure IV).

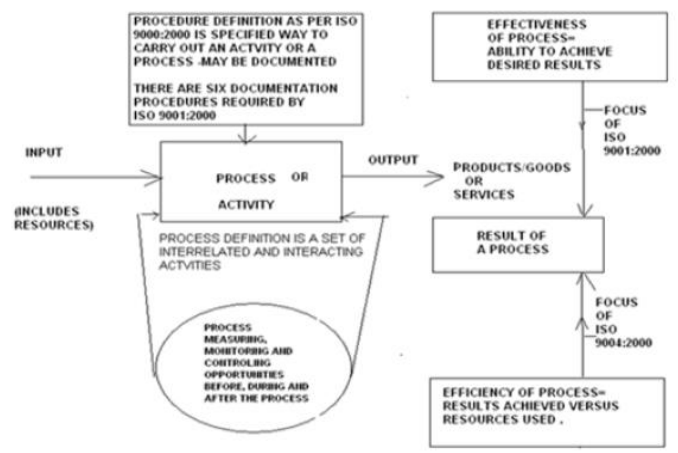

FIGURE IV. SCHEMATIC DIAGRAM OF A CONSTRUCTION PROCESS

The integration of environmental protection and economic development is the most important strategic environmental assessment tool in achieving sustainable development (Figure V). Project planning and decision-making should include the integrative consideration of engineering or technical, economic, environmental, ethical and social factors. A midget electrode project has been considered a special case study for the strategic environmental assessment process (Figures $\mathrm{V}$ and VI). International EIA process has been designed for the sustainable midget electrode project design and construction to identify and predict the potential effects of the physical, biological, ecological, socio-economic, cultural environment and on human health and well-being are adequately protected. 
Environmental Impact Statements (EIS) have been prepared for the project which considering environmental and socioeconomic factors with respect to development and other proposed actions. Therefore, the EIA system is a potentially useful component of good environmental management [2].

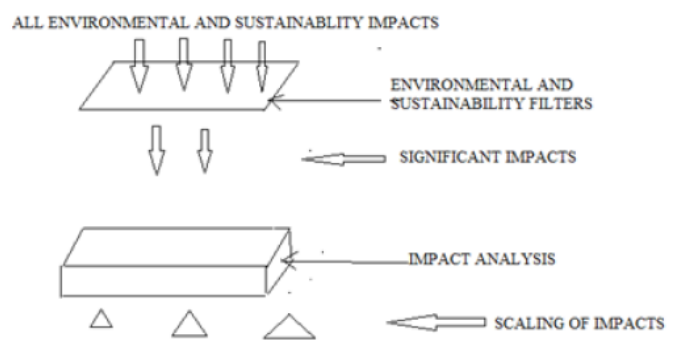

FIGURE V. PROCEDURE FOR FINDING OUT THE SIGNIFICANCE OF ENVIRONMENTAL AND SUSTAINABILITY EFFECTS

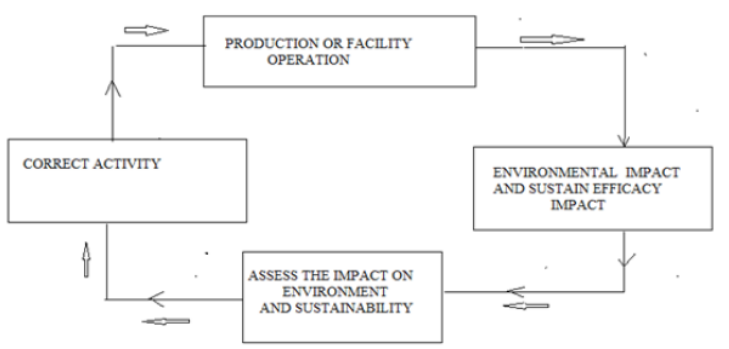

FIGURE VI. ENVIRONMENTAL AND SUSTAINABILITY ENTITLED "AFTER-THE-FACE" EVALUATION

In chromium tanning industry in Chromepet TamilNadu, India that environmental chromium contamination and pollution has discharged beyond safe limits which seriously affects the life on the earth. Toxic emissions from industries, thermal power plants, smelting pollution, auto exhaust pollution in large metropolitan areas, photo chemical smog have been poisoning the atmosphere beyond the permissible levels which causes serious health hazards. Air pollution causes adverse environmental health and social impacts. Mindless disposal of untreated industrial wastes in Odissa chromite mines and other radio-active wastes in nuclear power plants, construction debris, sanitary wastes, hazardous wastes, municipal solid wastes, agricultural wastes, domestic wastes have contaminated and polluted the water, soil and land beyond the tolerable limits, which adversely affects land fertility, water quality, vegetation, aquatic and marine life. This proves more and more hazardous as this development continuously damaging the environment viz., melting of glaciers, climate change, carbon tetra chloride emission, greenhouse gas emission, ozone layer depletion. For example, due to continuous increase in $\mathrm{CO}_{2}$ concentration in the atmosphere due to industrial emission of about $382 \mathrm{ppm}$ which lead to climate change. This decrease in glaciers contributes to about $29.5 \%$ of mean sea level rise since 1991. Water supplies stored in the glaciers were projected to decline. Besides contaminating and polluting air, water, soil and land, intensive technological activities lead to depletion of natural resources.

This must have been required to bring our energy and intellectual capacity in tandem whereby that can meet the challenge efficiently without major disruption as well as without compromising on the livelihood of future generation of their needs. Development would have occurred without damages to the environment and major disruption, and the process of urbanization and rural industrialization would have occurred in sustainable manner by utilizing the resources efficiently. Now, these environmental problems are the present environmental challenges and opportunities for improvement. To overcome these environmental problems that shall require new and more efficient solutions, technologies, processes and products alongside behavioral change.

Low carbon and energy efficient technology of construction industries can make contributions to mitigating impacts of economic growth on global warming (Figure VII) .The resultant output of green products and services which are environmental advantages with superior performance and cheaper prices. The dual goals of green design are the waste prevention and better material management as depicted in Figure VII. Design and construction of green buildings that has considerably reduced the environmental impacts associated with manufacturing, use and disposal. Prior to the enactment of National Environmental Policy Act on Environment in1970 in the USA, only technical or engineering and economic factors dominant in planning and decision-making process in most of the world projects, plans, programs, permits, policies and legislative actions. As per the research results that project planning and decision-making process must include the integrated consideration of engineering or technical, economic, environmental, safety, ethical, social and sustainability factors. This important consideration can be referred to as "Concept of the Four Es and $1 \mathrm{~S}$ " in organizational planning and decisionmaking process. There are ecological and biogeochemical principles and tools such as energy flows and material cycling, element ratios, mass and energy balance, element cycling, product environmental Lifecyle assessment (LCA)(Figure VIII) are available to solve major environmental problems that we face in our world today such as global warming, acid rain, environmental pollution and increasing greenhouse gases.

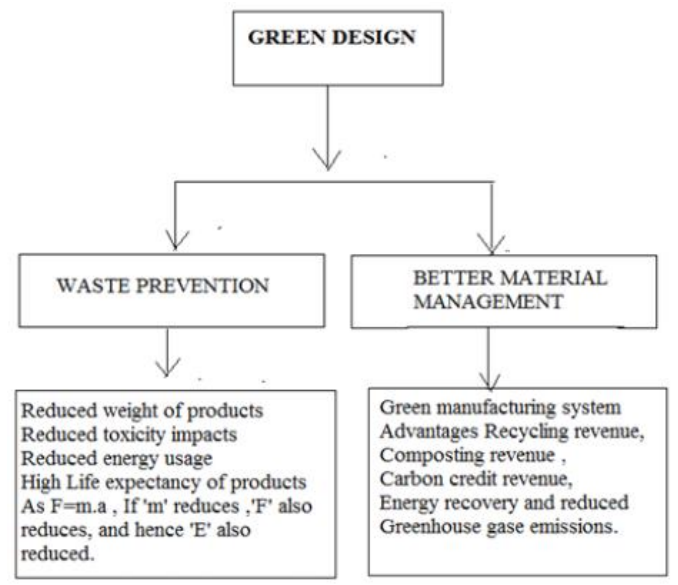

FIGURE VII. DUAL GOALS OF GREEN DESIGN AND MANUFACTURING PROCESS

Engineering product environmental lifecycle analysis (LCA) is conducted for identifying and measuring the impact of industrial products on the environment and sustain efficacy 
by means of mass and energy balance methods (Figure VIII). LCA consider the activities related to extraction of raw materials, ancillary materials, equipment production, use, disposal and ancillary equipment [2].

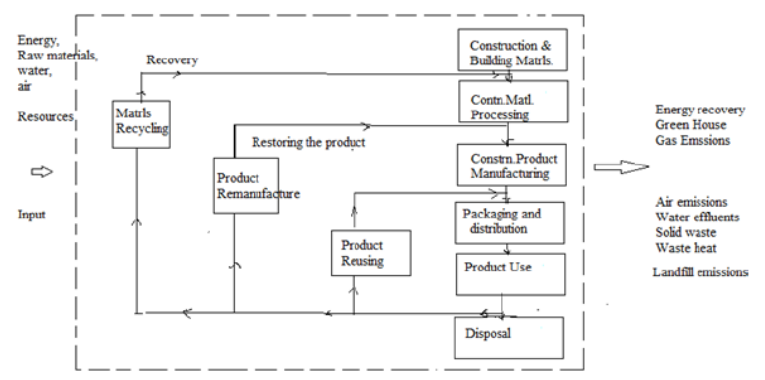

FIGURE VIII. CONSTRUCTION PRODUCT ENVIRONMENTAL LIFECYCLE ANALYSIS (LCA)

\section{A. Environmental Health Impact Assessment (EHIA) Process for Nuclear Power Plant Project towards Sustainable Constructional Development}

An environmental health impact assessment (EHIA) process is proposed in this research for nuclear power plant project during the construction phase to address psychological health impacts on workers and nearby residents. Environmental health impact assessment can be defined as the systematic identification and evaluation of the potential environmental health impacts or effects of proposed nuclear power projects, plans, programs, policies or legislative actions relative to the physical-chemical, biological, cultural and socioeconomic components of the total environment. At present there are more than four hundred thirty-seven nuclear power plants situated in the World. It may be worth mentioned that none of the nuclear power projects, plans, programs, policies, or legislative actions in the World have got sustainable practice in conduction of EHIA. Nuclear power plants generate electricity using heat generated in pressurized water reactors where nuclear reaction takes place. During the construction phase of nuclear power plants which use Uranium-235, Thorium-232 and Plutonium-239 as fuels in nuclear reactors causing nuclear fission. That time copious amount of radiation dose due to radioactive pollution escaping out in the order of about 120 billion Becquerel (120 GBq) to 240 billion Becquerel (240 GBq) that is 50 grams to 100 grams, radiation activities viz., Alpha $(\alpha)$, Beta $(\beta)$ and $\operatorname{Gamma}(\gamma)$ as against the safe limits of $0.1 \mathrm{~Bq} / 1$ or $\mathrm{Bq} / \mathrm{kg}$ (ppm) in land, air and water when operation, repair and maintenance of replacing old nuclear fuels with new fuels taken place. High exposures to radioactive pollution damage mental health and psychological burden on workers and nearby residents. As per a psychological health impact survey conducted by the author in a nuclear power plant at Quinson, China, severe psychological disorders including radioactive poisoning, depression and post-traumatic stress have been investigated to an extent among $49 \%$ of the nearby residents in and around $82 \%$ of the nuclear power plants in the World. Psychological health impact loadings due to radioactive environment on workers and nearby residents have been studied in this research during the test run phase using green information technology and management engineering systems.
Psychological health impact assessment (PHIA) on workers and nearby residents have been addressed to mitigate psychological health impact loadings on workers and nearby residents.

\section{B. Environmental Health Impact Assessment (EHIA) Process for Sustainable Development}

In this research, EHIA process has been investigated on cotton double roller (DR) ginning industries using chrome composite leather clad (CCLC) washers and design and development of an eco-friendly alternative. The objective is to assess the environmental health impacts of Indian cotton ginning industries. Most of the cotton ginning operations are performed by using DR ginning machines which serve a key role in the Indian cotton ginning industries. The rollers used are made of CCLC covering fixed to a shaft. The CCLC contains about 18,000 to $36,000 \mathrm{mg} / \mathrm{kg}$ (ppm) of chromium particles. When the seed-cotton is processed in DR ginning machine, the lint cotton is contaminated with hexavalent chromium dust of about 140 to $1990 \mathrm{mg} / \mathrm{kg}$ (ppm) which is carcinogenic substance against the safe limits of $0.1 \mathrm{ppm}$. During the cotton ginning process due to persistent rubbing of CCLC over stationary knife the chromium particles are adsorbed into lint cotton such that the spun yarns and woven fabrics get contaminated about 100 to $200 \mathrm{ppm}$ which according to World Health Organization (WHO) eco-standards should not be more than $0.1 \mathrm{ppm}$. The CCLC rollers used in cotton roller ginning machines get powdered during the ginning process. As chromium is a specific dust, gin and mill workers and residents are directly exposed to this carcinogenic substance and are vulnerable to environmental health hazards. To offset this problem, pollution-free eco-friendly washers/rollers both for laboratory and commercial studies have been fabricated and experimented. Environmental health inventory (EHI) serves as the basis for evaluating the potential environmental health impacts both beneficial and adverse of a proposed action. Environmental health impact statement (EHIS) describes the affected environmental health or environmental health setting without the project. Design and development of the EHI is an initial step in the EHIA process. It is concluded that EHIA process should be conducted for certain projects, plans, programs, legislative actions, policies in the project planning and decision-making process.

\section{International EIA Process}

International EIA process is a potentially good environmental management system (EMS). International organization for Standardization (ISO)'s 14000 and 9000 standards focus on Environmental Management System (EMS) and Quality Management System (QMS) of all sorts of organizations apart from more than 19500 published standards. Environmental Management System (EMS) and Quality Management System (QMS) have been separately featured in ISO. Environmental Management System (EMS) standards apply to the management system concepts of an organization's environmental issues and opportunities [1]. It defines the features of an EMS that need to be in place to ensure that the organization identifies and focuses on improving areas where they have significant environmental impacts. This system can be integrated with ISO 9000 Quality Management System 
(QMS) standards to achieve excellence in quality as well as environmental obligations. The overall aim of the EMS is to provide protection to the environment and to prevent pollution to manufacture eco-friendly products and services. EMS focuses on key drives of performance excellence in products and processes as well as organizations that are focused on delivering values to the customers, internal operational processes, and to staff's learning. Hence, this system approach to the environmental management shall achieve excellence in the overall performance of the organization. In the present study about two third of construction waste was recoverable due to the conduction intensive on-site training programs on recycling and composting processes as against the conventional construction management practices which could able to recover the waste of only 10 to $15 \%$.

Wastes are produced by industrial sector. The study has been attempted to identify and evaluate special waste minimization hierarchy of waste management for properly managing industrial waste including minimizing generation and treatment that have been generated and disposing of waste residuals. A case study has been included on generation of construction wastes and potential waste management strategies for a group or generic, source specific and specific industrial processes. All processes generate wastes in the form of liquids, solids or gases. IMCL wastes may be characterized and assessed as hazardous. The waste minimization hierarchy of waste management is duly ranked from most desirable to least desirable (Figure IX). 1. Eliminating waste generation - Most desirable, 2. Reducing waste generation- Most desirable, 3. Reuse, recover or recycle waste materials- Most desirable, 4. Treating waste to diminish quantity and to detoxify the hazardous and non-hazardous solid wastes --Least desirable, 5. Disposing of waste residuals- Least desirable. Waste minimization include only elimination, recovery, reduce, reuse and recycle hierarchies. Waste minimization does not include treatment of wastes as well disposal that is point number 4 and point number 5 because, these are traditional waste control strategies involves treatment and disposal which are called end-of-the pipe solutions and are costly affairs as well as involve control of high discharge standards. Modern waste control strategies involve point number 1, point number 2 and point number 3 which are not requiring end-of- the pipe solution for the waste management problems. Solid and hazardous waste generation is the sum of material recovery and discards. Report on waste audit conducted for a construction industry is presented for recovering two-third of municipal solid wastes (MSW) by recycling and composting processes (Figures X and Figure XI).

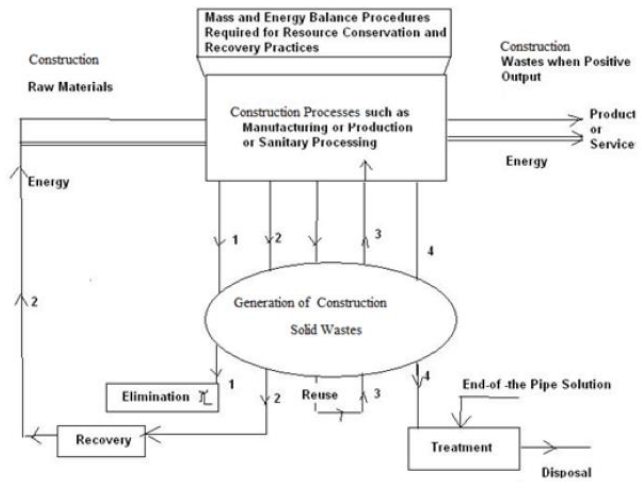

FIGURE IX. SCHEMATIC REPRESENTATION OF INDUSTRIAL PROCESS OR ACTIVITY SHOWING SUSTAINABLE WASTE MANAGEMENT

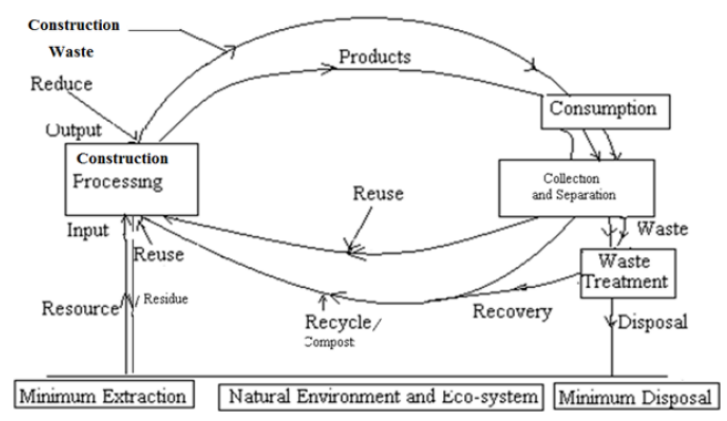

FIGURE X. CLOSED LOOP-SHAPED GREEN ECONOMY FOR SUSTAINABLE WASTE MANAGEMENT.

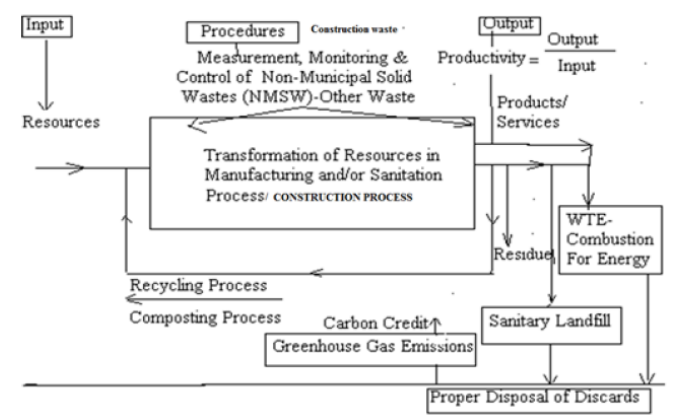

FIGURE XI. SUSTAINABLE WASTE MANAGEMENT SYETEM

To achieve the sustainable economic improvement, natural resources to be utilized at optimum level to maximize efficiency and maximize effectiveness as per the result analysis of optimum competitive and social markets. The efficiency of a kind of sustainable economic system is referred in " $A . K$ " sustainable economic model that is the product of engineering or technical factor level (A) and the capital (K). The sustainable economic improvement is explained by three factors which are given below: -

The natural increase in the accumulation of labor potential, capital accumulation or money with which a business is started and run; sustainable technological momentum can be referred as total factor productivity (TFP) or efficiency in construction process. 
Such momentum keeps the capital development dynamic which emerges from the sustainable enterprise creation process, green products or services, new methods of production and processes, new construction management and transportation, new markets and new forms of constructional organization.

Standard Production Function (SPF) is expressed based on operation approach as $\mathrm{Y}=\mathrm{f}(\mathrm{C}, \mathrm{L})$

Where $\mathrm{Y}=$ Output, $\mathrm{C}=$ Capital, and $\mathrm{L}=$ Labour

As knowledge is a crucial factor for the economic growth,

Standard Production Function (SPF) is modified based on process approach as

$$
Y=A . f\left(X_{1}, X_{2}, X_{3}, X_{4}, X_{5}, X_{6}\right)
$$

'A' represents Knowledge on sustainable constructional engineering or technical factor,

$\mathrm{Y}=$ Output,

Input elements are namely, man power, machinery, materials, method, money and market denoted as $\mathrm{X}_{1}, \mathrm{X}_{2}, \mathrm{X}_{3}$, $\mathrm{X}_{4}, \mathrm{X}_{5}, \mathrm{X}_{6}$

$\mathrm{f}=$ Standard production function.

As per the given standard production function, knowledge is a decisive production variation, sustainable innovation level is required in engineering or technical system. The solution is the development of reformed SEA process implemented industries for green information technology and management engineering systems.

\section{Importance for the Conduct of Environmental Impact Assessment (EIA) and Management Study for Certain Projects}

Historically, the choice of new constructional projects was primarily on one criterion, that is economic viability. Presently, second and third choice criteria that is environmental and social impact have become a strong yardstick, therefore a triple bottom-line approach that is economic, environmental and social factors to constructional project viability. Environmental Impact Assessment (EIA) process is a systematic identification and evaluation of potential effects of proposed projects, plans, programs, plans or legislative actions relative to the physical-chemical, biological, cultural and socio-economic components of the total environment.

1) Steps to conduct environmental impact assessment and management

Step-1: Identification of quantity and quality characteristics of concerned environment of proposed project.

Step-2: Preparation of description of existing environmental resource conditions.

Step-3: Procurement of relevant quantity and quality standards.

Step-4: Impact predictions,
Step-5: Assessment of impact significance,

Step-6: Identification and incorporation mitigation measures.

2) Conduct of Environmental Impact Assessment (EIA) Study for the efficient constructional industrial projects

Prediction and assessment of impacts on surface water environment,

Prediction and assessment of impacts on soil and ground environment,

Prediction and assessment of impacts on the air environment,

Prediction and assessment of impacts on the noise environment,

Prediction and assessment of impacts on the biological environment,

Prediction and assessment of impacts on the visual environment,

Prediction and assessment of impacts on socio economic environment.

Prediction and assessment of impacts on cultural environment,

Prediction and assessment of impacts on archaeological environment,

Prediction and assessment of impacts on anthropological environment

3) Benefits of EIA in construction industries

Considerable reduction in waste and the depletion of resources.

1. Considerable reduction and / or elimination of the release of pollutants in to the environment.

2. Green design and green building products to minimize their environmental impact in Production, use, and disposal.

3. Control the environmental impacts of sources of raw material.

4. Waste minimization and adverse environmental impact of new developments.

5. Promote environmental awareness among employees and the community.3.5.4 Environmental Management Programs

The organization shall establish and maintain a program(s) for achieving the environmental objectives and targets. It shall include designation of the responsible function, team, or individual and a time frame for achievement [1].

1. State the objective / target.

2. State the purpose (how the objective/target will support the policy).

3. Describe how the objective/target will be achieved.

4. State the program (team) leader.

5. Designate departments and individuals responsible for specific tasks.

6. Establish the schedule for completion of the tasks. 
7. Establish the program review, which will include format, content, and review schedule.

\section{E. Conduct of Social Impact Assessment (SIA) Study}

Social Impact Assessment (EIA) process is a systematic identification and evaluation of potential social effects of proposed projects, plans, programs, plans or legislative actions relative to the society. The purpose of the SIA process is to bring about a sustainable and equitable biophysical and human environment. SIA process includes the monitoring, measurement and control opportunities including analysis and management of the intended and unintended social consequences whether both positive and negative impacts of planned interventions and any changes takes place in social transformation process invoked by those interventions. The SIA process should include the analysis of the use of land, culture, industrial process, economic development, and their impact on service sectors such as water use, energy use, sanitation and traffic. SIA process is done to ensure that there is no mismatch between the constructional development and socio-cultural and economic development of the project areas.

\section{F. Safety Engineering and Management in Industries (Safety First)}

Safety management is the systematic identification and evaluation of potential safety requirements of proposed projects, plans, programs, plans or legislative actions. The purpose of the safety engineering and management is to bring about design and constructions of sustainable engineering structures. It has been observed that some construction methods and machineries used in India are to be obsolete and outdated because they were old which operated on poor performances in terms of productivity, quality, efficiency and safety. Some of the alternative machineries, which are indigenously manufactured, also do not guarantee for the superior performance and necessary safety conditions because of their poor design and materials of construction. It is mandatory that checking for safety requirements about machineries, bridges, roads and buildings. Safety personnel responsible for overseeing the safety of all operating personnel must be cognizant of the latest laws and regulations pertaining to worker safety and occupational health. These are changed and/or updated from time to time. Checking for Safety (CFS) such that to ensure that the question of safety will not be overlooked, it is well to have all plans, specifications and drawings checked for safety, making special provision for this in each set of specifications and in the title plate of each drawing duly checking periodically for cranes, hoists, ventilation, lifts, tackles, fire protection systems, alarms, buildings, mechanical guarding and electrical and electronic equipment and heavy engineering equipment's. Personal protective equipment (PPEs) and materials include garments, clothing, gloves, safety shoes, hard hats, safety glasses, shields, respirators, full aprons, safety belts, and other safety items must use by an individual. Such equipment is important for personal protection and for safety. It is the manager's and supervisor's responsibility to ensure that they are used. As far as occupational-disease prevention is concerned that those persons engaged in or working near operation are exposed to appreciable quantities of dusts, fumes or gas, it is important that adequate control measures must be adopted. Some major considerations involved in the application of effective control to industrial occupational disease are given. Some of the policies, practices, and procedures to prevent exposure of personnel to unsafe materials are also provided. As far as the worker's compensation law is concerned, it must be enacted strictly in our country. The principle involved is that the worker injured or disabled in construction industries should be enabled, through proper medical treatment, to return to wageearning capacity as promptly as possible and while incapacitated, should receive compensation in lieu of wages, and regardless of fault. The expense of medical treatment and compensation should properly be borne by industry and become a part of the cost of its products. The laws generally provide that workers injured in industry shall be furnished the necessary medical treatment, and, in addition, compensation based on a percentage of their weekly wages, payable periodically. Dependents of employees kill in industry are likewise compensated. Occupational diseases law provides provisions for compensation benefits in occupational - disease cases. The enactment of worker's compensation laws and occupational disease law shall increase materially the cost of insurance to industry. The increased cost and the certainty with which it is applied will put a premium on accidentprevention work. This cost can be materially reduced by the installation of safety devices. Research experience has shown that approximately $80 \%$ of all the construction industrial accidents are preventable. As far as the fire loss prevention is concerned, which is an indispensable element in construction industry. It exists only with top management direction and the support of labor. The designation fire protection usually encompasses the entire field of prevention of loss by fire, including both the causes for the occurrence of fires and methods for minimizing their consequence. Some of the fire standards of protection to prevent injury and loss of life are given in this paper. Fire protection engineering practices both in building design and in safe operating practices are also included. Construction noise safety is concerned, noise is recognized as a pollutant, both as a nuisance and as the cause of hearing impairment. There is evidence in construction sites that noise cause ailment such as hearing impairment, physiological and psychological disorders including anxiety and heart disorders. Protection from noise is required when sound levels exceed those standards. When protective equipment is required, it must be provided by a trained person and periodic checks made of the effectiveness [7].

\section{G. Total Quality Management (TQM)}

Total Quality Management (TQM) can be broadly defined as a set of systematic activities carried by an institution to efficiently achieve institutional objectives that satisfies beneficiaries at the appropriate time and price. The definition of quality is "The totality of features and characteristics of products or services that bear on its ability, efficacy and values to satisfy a given or implied need". TQM is a comprehensive and structured approach to an educational integrated management that seeks to improve the quality of educational services through ongoing refinements in response to continuous feedback. Thus this standard definition of quality is applicable commonly to both products and services that is 
stated and unstated [1].TQM has an important role to play in addressing quality issues surrounding the constructional development. TQM is a comprehensive and structured approach to construction sector that seeks to improve the quality of services through ongoing refinements in response to continuous feedback. TQM leads to sustainable constructional development. International Organizational for Standardization's ISO 9000 series define TQM as a management approach centered on quality, based on the participation of all its members and aiming at long term success through customer satisfaction and benefits to all members of the organization and society. Hence, TQM is based on quality management from the customer's point of view. TQM processes are divided into four sequential categories: plan, do, check, and act (Figure XII). This is also called the PDCA cycle or Deming's cycle for continuous process improvement. In the planning phase, constructionists define the problem to be addressed, collect relevant data, and ascertain the problem's root cause; in the doing phase, constructionists develop and implement a solution, and decide upon a measurement to gauge its effectiveness and efficiency; in the checking phase, constructionists confirm the result through before-and-after data comparison; in the acting phase, constructionists document their results, inform others about process changes, and make recommendations for the problem to be addresses in the next PDCA cycle. ISO 9000 series focus on quality management for all sorts of organizations. It defines the features of quality management system (QMS) that need to be in place to ensure that identify and focus on improving the areas where they have significant constructional deficiencies [1].

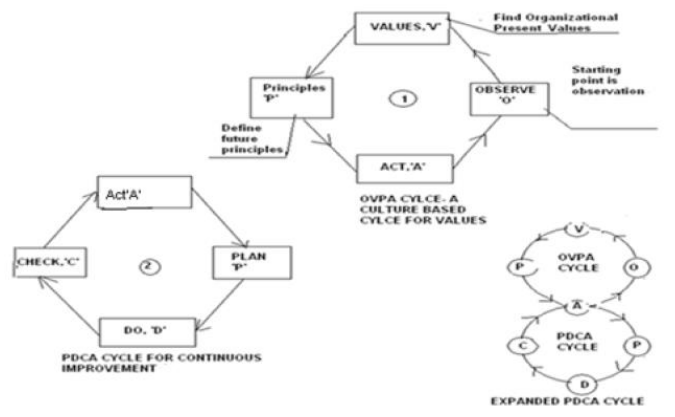

FIGURE XII. CONCEPTUALIZATION OF CULTURE BASED ENVIRONMENTAL AND QUALITY MANAGEMENT ENTITLED" OVPA" CYCLE BY INCORPORATING THE EXPANDED PDCA CYCLE

The ISO 14000 Environmental Management System (EMS) standards apply to the management system to manage an organization's environmental issues and opportunities [1]. It defines the features of an EMS that need to be in place to ensure that the organization identifies and focuses on improving areas where they have significant environmental impacts. This system has been integrated with ISO 9000 Quality Management System (QMS) standards to achieve excellence in quality as well as environmental obligations in midget electrode project. The overall aim of the EMS is to provide protection to the environment and to prevent pollution to manufacture eco-friendly products and services. The ISO
14000 series of standards assist the organizations to excel environmental and economic gains for continuously improving organizational performances. They are used for prevention of pollution, reduction in wastes, enhancement of internal management system efficiency, optimum utilization of resources and compliances for legal and regulatory requirements. EMS can be basically divided into five events which form the sequence of a cycle (Figure XIII). These five events are (1) Environmental Policy, (2) Environmental Planning, (3) Environmental implementation and operations, (4) Checking and corrective actions, and (5) Management Review. The ISO 14000 series of standards have also been designed to cover the areas of environmental issues and opportunities for the organizations to compete the global customer centric markets so that the products and services can be manufactured at par with the international requirements [1].

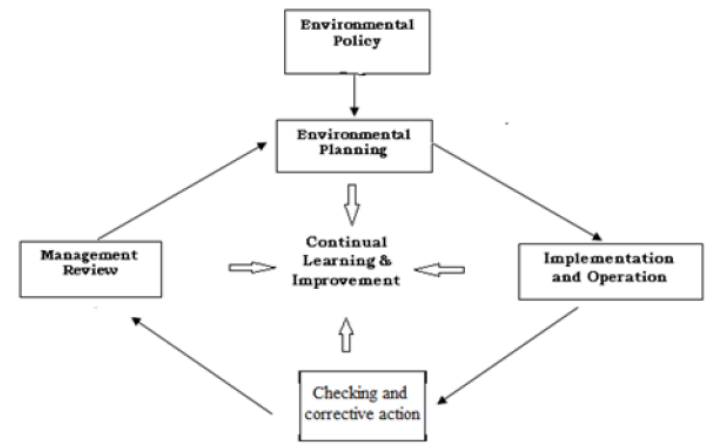

FIGURE XIII. ENVIRONMENTAL MANAGEMENT SYSTEM

EMS focuses on key drives of performance excellence in products and processes as well as organizations that are focused on delivering values to the customers, internal operational processes, and to staff's learning. It may be mentioned that Environment and Quality Management (EQM) is a managerial approach centered on environment and quality through beneficiary satisfaction in construction industries that lead to economic improvement and sustainability. Hence, this system approach to the environmental management shall achieve excellence in the overall performances of the organization.

\section{CONCLUSIONS AND RECOMMENDATIONS}

Sustainable education process is a kind of development that meets the needs of the present without compromising the ability and efficacy of future generations to meet their own educational needs. In this research article, strategic environmental assessment (SEA) process for environmental engineering systems has been discussed. Strategic environmental assessment process (SEA) can be defined as the systematic identification and evaluation of the potential strategic environmental impacts of proposed projects, plans, programs, or legislative actions relative to the physicalchemical, biological, cultural, and socio-economical components of the total strategic environment. The primary purpose of the SEA process is to encourage the consideration of the sustainability in planning and design making process and to ultimately arrive at actions which are sustainably compatible. SEA process has been aimed to incorporate 
environmental and sustainability factors in to organizational project planning and decision-making process, such as projects' formulation and appraisal of Indo-Matsushita midget electrode (battery carbon rod) plant in 1979 at Tada, cotton roller ginning plant and certain other projects that included polices, programs, plans and legislative actions. The primary purpose of the SEA process is to encourage the consideration of the environment, safety, health, social and sustainability factors in organization's planning and decision making (OPDM) process and to arrive at actions that are compatible. EIA industrial process should be considered as an official tool to protect the environment. Sanitation impact assessment has been investigated for sanitary projects and plans. EIA process is a multidisciplinary approach that must be necessary in providing a prevention mechanism for environmental management and protection in any sustainable industrial developmental projects. EIA process is designed to identify and predict the potential effects of the physical, biological, ecological, socio-economical, cultural environment and on human health and well-being are adequately protected [8].

As per research results, OPDM process should include the integrated consideration of technical or engineering, economic, environmental, safety, health, social and sustainability factors to achieve business excellence. The SEA process protocol has been proposed for checking the quality of environmental and social assessments and management plans. This treaty and official government procedures of SEA process helpful for making much earlier in the decision-making process than EIA process. Therefore, it is key tool for sustainable educational process. SEA process aims to incorporate environmental and sustainability considerations in to strategic decision- making processes, to formulate policies, plans, and programs and legislative actions.

Prior to the National Environmental Policy Act (NEPA) process in 1970 in the USA, technical and economic factors dominance the World's constructional projects. The objective of the study is to design conceptualize SEA process for the industrial sector based on fifteen number of sustainable detailed project reports submitted by the extension learners of Diploma in Entrepreneurship and Business Management (DEBM) course conducted by the Entrepreneurship Development Institute of India (EDII) during the research year 1999 to 2018 under the author's counsellorship. The ISO 14000 Environmental Management System (EMS) standards apply to the management system concepts of total quality management to the management of an organization's environmental and quality issues and opportunities. It defines the features of an EMS that need to be in place to ensure that organizations identify and focus on improving areas where they have significant environmental and quality impacts. EMS focuses on key drives of performance excellence in products and processes as well as organizations that are focused on delivering values to the customers, solving internal operational processes, and to staff's continuous learning process. Hence, this system approach to the environmental management shall achieve excellence in the overall organizational performance. Engineering product environmental lifecycle analysis has been conducted for identifying and measuring the impact of industrial products on the environment and sustain efficacy by means of mass and energy balance methods. LCA considers the activities related to raw materials, transformation, ancillary materials, equipment, methods, market, production, use, disposal and ancillary equipment. As far as the industrial safety is concerned, personal protective equipment and materials that include garments, clothing, gloves, safety shoes, hard hats, safety glasses, shields, respirators, full aprons, safety belts, and other safety items must use by an individual. Such equipment is important for personal protection and for safety. It is the manager's and supervisor's responsibility to ensure that they are used [9]. The enactment of worker's compensation laws and occupational disease law shall increase materially the cost of insurance to industry. The increased cost and the certainty with which it is applied will put a premium on accident-prevention work. This cost can be materially reduced by the installation of safety devices. Constructional management research experience has shown that approximately $80 \%$ of all the construction industrial accidents are preventable. It is concluded that eenvironment coupled with quality management is a managerial approach centered on environment and quality through beneficiary satisfaction that leads to economic improvement and sustainability based on the triple bottom-line approach. TQM has a key role to play in addressing quality issues surrounding the sustainable constructional development. Sustainable water and waste water management has been discussed.

EIA and EHIA processes have been conducted for certain projects to consider the safety and health impacts to mitigate psychological health loadings on workers and nearby residents. SEA process system is a potentially useful element of good environmental management and sustainable education development; however, as currently practiced in information technology and management engineering industries, it is far from perfection. Emphasis should be given in industries on maintaining economic viability of the operation, while in turn taking care to preserve the ecological and social sustainability of the country. International EIA process required multidisciplinary approach that has been conducted very early stage of Indo-Matsushita carbon rod (MCC) project in 1982 at Tada for economic, environmental and social viabilities [10] concerning green information technology and management engineering systems.

\section{ACKNOWLEDGEMENT}

This research was financially self-supported. The author is thankful to Sri. Koneru Satyanarayana, President, Koneru Lakshmaiah Education Foundation (KLEF) Deemed To Be University, Vaddeswaram, Guntur, Andhra Pradesh, India for giving permission to publish this research paper. The author is thankful to the organizers of 2018 International Conference on Information Technology and Management Engineering (ITMEC2018) http://www.itmeconf.org/com held during August 26-27, 2018 Beijing, China for International Scientific Committee Member service requisition and publication of this research paper in the proceedings on Advances in Intelligent Systems Research (ISSN: 1951-6851) published by Atlantis Press. 


\section{REFERENCES}

[1] Giri.,C.C. et.al.(2003), Importance of the ISO 14000 in Textile Industry and its Implementation Framework, Journal of Textile Association, JulyAug.2003, pp.5763 (2003)

[2] Glynn Hendry J and Gary W.Heinke, (2002)“ Environmental Science and Engineering", Prentice -Hall of India Private Limited Second Edition, 2002.

[3] Ralph A.Wurb, (2010) "Water Resources Engineering", Prentice -Hall of India Private Limited, 2010 edition.

[4] Metcalf\& Eddy, Inc.(2012) "Wastewater Engineering, Treatment and Reuse, McGraw Hill Education (I) Private Ltd. 2012 Edition.

[5] Larry W. Canter, "Environmental Impact Assessment", McGraw-Hill International Editions 1996, Second Edition (ISBN 0-07-114103-0), PP.2.

[6] Iyer Vijayan Gurumurthy(2015), "Environmental and Quality Management for the Higher Education Institutions to Achieve Research and Academic Excellence", Journal of Modern Education Review (JMER), ISSN 2155-7993,USA, November 2015, Volume 6, Number 2, PP. 135-146 (12 pages) @Academic Star Publishing Company 2015, http://www.academicstar.us.

[7] Iyer, Vijayan Gurumurthy (2018). "Strategic Environmental Assessment (SEA) Process Towards Sustainable Construction Management Development for the Electrical, Automation and Mechanical Engineering Construction Industries to Achieve Business Excellence". In the Proceedings and Abstract Book of the 20183 rd International Conference on Electrical, Automation and Mechanical Engineering (EAME2018) CD-ROM, http://www.eame2018.org/June 24-25, 2018 Xi'an, China and as General Chair of EAME 2018 , Publication by Atlantis Press (Open Access Scientific Publishing) book entitled "Advances in Engineering Research (AER) (ISSN:2352-5401) Published by Dr.Vijayan Gurumurthy Iyer, Editor of AER.

[8] Iyer, Vijayan Gurumurthy (2018). "Study of Reciprocal Accountability and Total Quality Management in Education Sector and Its Ideal Implementation Towards Sustainable Development". In the Proceedings and Abstract Book of the International Conference on Computational Modelling, Simulation and Mathematical Statistics (AMMSA2018) CDROM held during May 27-28, 2018 at Sanya, China and as Edtior/General Chair of AMMSA2018 http://www.ammsa2018.org/com.html May 27-28 Publication by Atlantis Press (Open Access Scientific Publishing) of series of Book entitled "Advances in Intelligent Systems Research (AISR), pp.402-411, ISBN: 978-94-6252-529-0, ISSN 1951-6851 volume: 443; Published by Dr.Vijayan Gurumurthy Iyer, Editor of AISR. Publication date June 2018. https://www.atlantis-press.com/proceedings/ammsa-18/publishing

[9] Iyer, Vijayan Gurumurthy (2018). "Total Quality Management (TQM) or Continuous Improvement System (CIS) in Education Sector and Its Implementation Framework Towards Sustainable National Development". In the Proceedings of the ASSEHR 2018 International Conference on Education Reforms and Management Science (ERMS2018) CD-ROM held at Wuhan, China during April 22-23 Beijing, China as General Chair of ERMS2018, http://www.erms2018.org/ Published by Atlantis Press (Open Access Scientific Publishing) in the Book entitled "Advances in Social Science, Education and Humanities Research (ASSEHR)", (ISBN: 978-94-6252524-5, ISSN 2352-5398) Published by Dr. Vijayan Gurumurthy Iyer, Chair/Editor of ASSEHR, pp.133-147.

[10] Iyer, Vijayan Gurumurthy (2018). "Total Quality Management (TQM) in Education Sector and Its Implementation Framework Towards Sustainable International Development". In the Proceedings of the 2018 International Conference on Computer Science, Electronics and Communication Engineering (CSECE2018) CD-ROM held at Wuhan, China during February 7-8, 2018 as General Chair of CSECE2018, http://www.csece2018.org, Book entitled "Advances in Computer Science Research (ACSR), Volume 80, ISSN: 2352-538X, ISBN 97894-6252-487-3 Published by Editor Dr.Vijayan Gurumurthy Iyer, Editor of ACSR, . doi:10.2991/csece-18.2018.119. Atlantis Press (Open Access Scientific Publishing), pp. 546-555.

[11] Iyer, Vijayan Gurumurthy (2017). "Total Quality Management (TQM) in Education Sector and Its Implementation Framework Towards Sustainable National Development". In the Technical Volume
Proceedings of the $32{ }^{\text {nd }}$ Indian Engineering Congress, Theme entitled "Innovation in Engineering: Competitive Strategy Perspective" (ISBN: 978-93-86724-29-8) held during $21^{\text {st }}-23$ rd December 2017 at Chennai Organized by The Institution of Engineers (India) Published by Excel India Publishers, New Delhi, Proceedings page number 412-421.

[12] Iyer, Vijayan Gurumurthy (2018). "Strategic Environmental Assessment (SEA) Process Towards Sustainable Construction Management Development for the Electrical, Automation and Mechanical Engineering Construction Industries to Achieve Business Excellence". In the Proceedings pp.87-96 and Abstract Book pp.16-17 of the 20183 rd International Conference on Electrical, Automation and Mechanical Engineering (EAME2018) CD-ROM, http://www.eame2018.org held during June 24-25, 2018 Xi' an, China and as General Chair of EAME 2018, Page numbers 87-96, An open access article published by Atlantis Press (Open Access Scientific Publishing) book entitled "Advances in Engineering Research (AER) ISSN: 2352-5401 (Volume 127), ISBN: 978-94-6252-538-2, Publication date July 2018 Editor by Dr.Vijayan Gurumurthy Iyer. https://www.atlantis-press.com/ 